\title{
PARISSCHOQL OF ECQNOMICS
}

WORKING PAPER Nº 2017 - 30

A mechanism design approach to the Tiebout hypothesis

Philippe Jehiel

Laurent Lamy

JEL Codes:

Keywords: mechanism design, competing mechanisms, endogenous entry, Tiebout hypothesis, local public goods

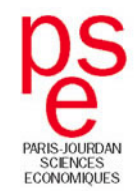




\title{
A mechanism design approach to the Tiebout hypothesis*
}

\author{
Philippe Jehiel ${ }^{\dagger}$ and Laurent Lamy ${ }^{\ddagger}$
}

\begin{abstract}
We revisit the Tiebout hypothesis in a world in which agents may learn extra information as to how they value the various local public goods once located, and jurisdictions are free to commit to whatever mechanism to attract citizens. It is shown in quasi-linear environments that efficiency can be achieved as a competitive equilibrium when jurisdictions seek to maximize local revenues but not necessarily when they seek to maximize local welfare. Interpretations and limitations of the result are discussed.

Keywords: mechanism design, competing mechanisms, endogenous entry, Tiebout hypothesis, local public goods.
\end{abstract}

\section{Introduction}

The so called free riding problem (Samuelson (1954)) is a well-known source of inefficiency attached to the provision of public goods. An informational version of it can be described as follows. Agents interested in the implementation of public goods may pretend they are less so in an attempt to reduce the price they have to pay for it, relying on others' contributions to ensure that the public goods are provided. To the extent that citizens can freely choose their jurisdictions viewed as competing public good providers, Tiebout (1956) suggested that the free riding problem should be alleviated given that citizens would sort efficiently according to their preferences. ${ }^{1}$ According to the Tiebout hypothesis, the competition between jurisdictions together with the option of citizens to vote with their feet would induce efficient outcomes in the context of locally provided public goods. The Tiebout hypothesis has been highly influential in a number of policy debates including schooling issues (Hoxby (2000,2007), Rothstein (2007)), residential segregation (Benabou (1993), Bayer and

\footnotetext{
${ }^{*}$ We thank the editor (Ali Hortaçsu), two anonymous reviewers as well as seminar participants at the Warwick theory workshop, Bonn University, EUI, UCL, Ecares, and Princeton for helpful comments.

${ }^{\dagger}$ Paris School of Economics (Ecole des Ponts, ParisTech) and University College London. e-mail: jehiel@pse.ens.fr. Jehiel thanks the European Research Council for financial support.

${ }^{\ddagger}$ CIRED (Ecole des Ponts, ParisTech). e-mail: laurent.lamy78@gmail.com.

${ }^{1}$ It is not so clear however if there are several types of citizens who would join the same jurisdiction how the free riding problem would be completely eliminated.
} 
McMillan (2012)) and decentralization issues (see Oates (1972), or Boadway and Tremblay (2012) and Baicker, Clemens and Singhal (2012) for more recent contributions). ${ }^{2}$

There have been several attempts to formalize the Tiebout hypothesis within the general equilibrium (henceforth GE) framework, typically assuming there is excess supply of jurisdictions so that in equilibrium jurisdictions (assumed to be revenue-maximizers) make zero-profit. When a single price is attached to membership (or to the consumption of the public good), efficiency is not guaranteed as shown in Bewley (1981) because heterogeneous pricing (of the Lindhal type) would be required when jurisdictions are populated by heterogeneous citizens. Assuming that preferences are revealed once citizens have chosen their locations, efficiency is typically implied by the equilibrium notion considered in those models, once allowing for heterogeneous preference-dependent access prices. This is so because in the logic of coalitional deviations, if a more efficient composition existed, a jurisdiction could propose it and make positive profit. A remaining issue is whether an equilibrium exists: This is typically not so in finite economies and can be shown to be so in continuum economies (see e.g. the surveys of Scotchmer (2002) and Wooders (2012)). Only a few papers in the literature consider the possibility that the preference type of citizens remains private information even after the location decision (Ellickson et al. (1999), Allouch, Conley and Wooders (2009) or Konishi (2013) for example) in which case additional constraints prevail on the pricing and the efficiency criterion (equal treatment if there is common access to the public good or extra incentive constraints if various types get access to different positions as in Konishi (2013)). A few other papers allow for moral hazard interactions once located, and then jurisdictions/firms are viewed as competing in contracts (Prescott and Townsend (2006), Zame (2007), Scotchmer and Shannon (2010)). It should be noted that none of these papers allow citizens to receive additional information once located. To sum up, in the previous GE approaches to the Tiebout hypothesis, efficiency is generally immediately implied by the equilibrium notion, and the challenging issue is whether an equilibrium exists. ${ }^{3}$ Importantly, these approaches also implicitly assume that citizens can freely coordinate on who joins a given jurisdiction, thereby justifying the kind of coalitional deviations needed to support efficiency.

We adopt a different approach in this paper. First, we explicitly allow, in (general) public good contexts, for asymmetric information to be received by citizens both before and after the location choice so as to capture that many opportunities in relation to local public goods become clearer once located. The post location information typically results in the

\footnotetext{
${ }^{2}$ Direct tests of actual migratory responses to public good provision are less common (see Banzhaf and Walsh (2008) for an example with (local) pollution and references on the topic).

${ }^{3}$ This is typically obtained in continuum economies using the techniques summarized in Duffie and Sun (2007)).
} 
heterogeneity of preferences ex post irrespective of the location choices of citizens, thereby calling for elicitation procedures (that were not considered in the GE approaches to the Tiebout hypothesis). ${ }^{4}$ This is modeled through the apparatus of mechanism design. Jurisdictions which may differ in many characteristics (assumed for simplicity to be observable) post mechanisms that determine the local public goods and taxes to be paid by citizens ex post as a function of their reports. Based on the profile of posted mechanisms, citizens sort into the various jurisdictions where we assume that ex ante identical citizens use the same location strategy. ${ }^{5}$ A continuum of citizens and jurisdictions is considered. This implies that a single choice of mechanism by one jurisdiction does not affect the equilibrium utilities of the different types of citizens. It also implies that the number of citizens of a given ex ante type entering a given jurisdiction is stochastic and governed by a Poisson distribution. ${ }^{6}$ Our main extra assumptions are that the private information of a citizen concerns his own preference only (private value environment), taxes enter in an additive way (quasi-linear environment) and optimal sizes of jurisdictions are bounded (congestion assumption). Other than that, our framework is very permissive allowing for general information structure involving multi-dimensional and correlated private signals. In equilibrium, jurisdictions post mechanisms that maximize their objective anticipating the effect of the mechanism on the location choices and the equilibrium choices of citizens' reports after the location choice, and citizens sort in the various jurisdictions and report their ex post preferences in a way that serves their interests best.

Our main result is that if jurisdictions seek to maximize local revenues (defined as the sum of collected taxes minus the cost of the public goods), one equilibrium outcome of the above competitive environment is the first-best welfare-maximizing outcome in which (1) public goods are efficiently chosen in each jurisdiction, and (2) citizens are efficiently distributed across jurisdictions (from an ex ante perspective). In our efficient equilibrium, jurisdictions all post the pivot mechanism, i.e. the VCG mechanism ${ }^{7}$ in which citizens are charged the welfare loss their presence causes on others. While the pivot mechanism like other VCG mechanisms is well known to guarantee ex post efficiency, it also ensures that the efficient participation decisions can be sustained as a free mobility equilibrium because citizens' payoffs in such a mechanism correspond exactly to their contribution to the local

\footnotetext{
${ }^{4}$ While in Konishi (2013), there is some heterogeneity in the formed jurisdictions because agents can be assigned different roles/positions, no heterogeneity arises in Allouch et al. (2009) in which all citizens are exposed to the same public good. Anyway, because there is no post location information and citizens can coordinate their participation decisions, mechanism design is absent from these contributions.

${ }^{5}$ This symmetry assumption will imply mixing and it is a key departure from the modeling in GE models in which, as reminded above, it is typically assumed that citizens can coordinate their participation decisions.

${ }^{6}$ Such distributions are familiar in the directed search literature (Rogerson et al. (2005)). They correspond to the limit of the sum of binomial distributions that would arise in finite economies.

${ }^{7}$ VCG is an acronym for Vickrey (1961), Clarke (1971) and Groves (1973).
} 
welfare. Since jurisdictions' objectives can be re-written as the local welfare net of the opportunity costs of participating citizens, the decentralization result follows.

Interestingly, if jurisdictions are instructed to maximize local welfare, inefficiencies may necessarily arise. Our result gives thus some support to the idea that local public goods should be managed privately (we discuss at the end a number of limitations of this conclusion). It should also be mentioned that whenever all jurisdictions receive positive participation in equilibrium (efficient jurisdictions are scarce), those jurisdictions typically make strictly positive expected profits. Thus, our efficiency result is not driven by a cutting price argument as in the Bertrand model or the previous GE approaches to the Tiebout hypothesis. ${ }^{8}$ Our framework also allows us to shed a new light on applications typically not considered in local public good contexts such as two-sided markets and competing exchange platforms.

Our decentralization result can be viewed as generalizing an insight appearing in the competing auction literature (the seminal contribution being McAfee (1993)) that has highlighted the emergence of second price auctions with reserve prices set at the seller's valuation, insofar as such a second price auction corresponds to the pivot environment in single-object auction environments. It should be mentioned that in our general environment, it may be optimal to split unevenly ex ante identical citizens across similar jurisdictions due to economies of scale, which contrasts with auction environments. Our decentralization result takes care of uneven splitting through the introduction of public correlation devices.

The rest of the paper is structured as follows. In Section 2 we describe the economic environment. In Section 3 we describe the competitive equilibrium. Our decentralization result appears in Section 4. Extensions and limitations are discussed in Section 5.

\section{The economic environment}

\subsection{The various agents in the economy, their information and preferences}

Jurisdictions: There is a continuum of jurisdictions. Each jurisdiction $j$ is characterized by a publicly observed type $k_{j}$ belonging to a finite set $\mathcal{K}_{J}$. The mass of type $k_{j}$ jurisdictions is denoted by $f_{J}\left(k_{j}\right)$.

Citizens: There is a continuum of citizens coming from finitely many groups in $\mathcal{K}_{C}$. Every citizen $i$ belongs to one group $k_{i} \in \mathcal{K}_{C}$, where groups are also referred to by an index $k \in\{1, \ldots, K\}$ and $K$ refers to the cardinality of $\mathcal{K}_{C}$. The mass of group $k$ citizens is denoted by $f_{C}(k)$. After joining a jurisdiction, any given citizen $i$ learns his (ex post) type

\footnotetext{
${ }^{8}$ Epple and Zelenitz (1981) also obtain that revenue-maximizing jurisdictions may make positive profits when the market becomes competitive. Since they do not include jurisdiction's rents in their welfare criteria, they interpret this as a source of inefficiencies.
} 
$\theta_{i} \in \Theta$ which fully characterizes his preferences over the various possible public goods in the jurisdiction. The set $\Theta$ together with a $\sigma$-algebra on $\Theta$ defines a measurable space. Without loss of generality, the private signal $\theta_{i}$ includes the group to which $i$ belongs, and we let $\mathbf{k}: \Theta \rightarrow\{1, \ldots, K\}$ denote the function that maps any citizen's type into his group. Conditional on the realization $y$ of a variable $Y$, the types of the various citizens in a jurisdiction with type $k_{j}$ are distributed independently and according to the measure $f_{k}\left(. \mid y, k_{j}\right)$ for a citizen of group $k$. The variables $Y$ (assumed to belong to a measurable space) are distributed independently across jurisdictions according to some measure $f_{Y}($.$) .$ Such a statistical representation allows us us to cover general patterns of correlations between citizens' valuations.

Consider a given jurisdiction with $n$ citizens, and a profile of types denoted by $\theta=$ $\left(\theta^{1}, \ldots, \theta^{n}\right) \in \Theta^{n}$. We let $\bar{\Theta}:=\bigcup_{n \in \mathbb{N}} \Theta^{n}$ denote the set of all possible profiles $\theta$ for all possible sizes $n$ of jurisdictions. For any $k \in \mathcal{K}_{C}$, we let $\theta^{[k]}$ be the subvector of types in $\theta$ of the citizens coming from group $k$, namely the profile of $\theta_{i}, i \in\{1, \ldots, n\}$, such that $\mathbf{k}\left(\theta_{i}\right)=k$. The length of the vector $\theta^{[k]}$ is denoted by $n_{k}(\theta)$. We let $n(\theta):=\left(n_{1}(\theta), \ldots, n_{K}(\theta)\right)$ and $\widetilde{n}(\theta):=\sum_{k=1}^{K} n_{k}(\theta)$. For a given profile $\theta$ and a given citizen $i \in\{1, \ldots, \widetilde{n}(\theta)\}$, we adopt the convention $\theta_{-i}=\left(\theta_{1}, \ldots, \theta_{i-1}, \theta_{i+1}, \ldots, \theta_{\widetilde{n}(\theta)}\right)$. With a slight abuse of notation, we let $\theta=\theta_{i} \cup \theta_{-i}$. We refer to $\mathbf{k}(\theta)$ as the profile of citizens' group membership associated with the type profile $\theta$, i.e. $\mathbf{k}(\theta):=\left(\mathbf{k}\left(\theta_{1}\right), \ldots, \mathbf{k}\left(\theta_{\widetilde{n}(\theta)}\right)\right)$. For $N=\left(n_{1}, \ldots, n_{K}\right) \in \mathbb{N}^{K}$ and $k_{j} \in \mathcal{K}_{J}$, we let $q\left(\theta \mid N, k_{j}\right)=\int_{Y} \prod_{k=1}^{K} \prod_{i=1}^{n_{k}(\theta)} f_{k}\left(\theta_{i}^{[k]} \mid y, k_{j}\right) \cdot f_{Y}(y) d y$ denote the density of $\theta$ in a jurisdiction with type $k_{j}$ conditional on $n(\theta)=N .^{9}$

Local public goods: Each jurisdiction provides a local public good $z$ in exchange for possibly citizen-specific taxes. Let $\mathcal{Z}_{n}$ denote the non-empty and finite set of feasible public goods in a jurisdiction with $n$ participants, and let $\mathcal{Z}:=\bigcup_{n \in \mathbb{N}} \mathcal{Z}_{n}$ denote the set of all possible public goods when varying the size of the jurisdiction.

Citizens' preferences are assumed to be quasi-linear. That is, citizen $i$ with type $\theta_{i}$ enjoying the public good $z$ in exchange for a tax $t_{i} \in \mathbb{R}$ gets an overall payoff of $v\left(z, \theta_{i}\right)-t_{i}$ where $v: \mathcal{Z} \times \Theta \rightarrow \mathbb{R}$ is a common measurable function that applies to all. ${ }^{10}$ Any citizen from group $k$ has also the option not to enter any jurisdiction, in which case he gets a default expected utility $\underline{V}_{k}>0$.

Jurisdictions are characterized by a type-dependent cost function $C: \mathcal{Z} \times \mathcal{K}_{J} \rightarrow \mathbb{R}$ where $C\left(z, k_{j}\right)$ denotes the cost of providing the public good $z$ when the jurisdiction is of type $k_{j}$. We assume that when one more citizen joins, the jurisdiction has always the option to put this citizen aside and provide a feasible public good to the remaining citizens. This is

\footnotetext{
${ }^{9}$ Whenever $n(\theta) \neq N$, then we let $q\left(\theta \mid N, k_{j}\right)=0$.

${ }^{10}$ This is without loss of generality, since any citizen specific dependence can be captured through the dependence in $\theta_{i}$.
} 
formalized by assuming that $\mathcal{Z}_{n} \subseteq \mathcal{Z}_{n+1}$ for any $n \in \mathbb{N}$, and if $z \in \mathcal{Z}_{n-1}$, then the left aside citizen $i$ gets a gross utility normalized to zero $\left(v\left(z, \theta_{i}\right)=0\right) .{ }^{11}$ In other words, the public goods we are considering are excludable local public goods. We assume that $\mathcal{Z}_{0}=\left\{z^{0}\right\}$ with the normalization $C\left(z^{0}, k_{j}\right)=0$ where $z^{0}$ can be interpreted as representing a situation with no public good.

Local welfare: The ex post local welfare function depends on the public good $z$, the type of the jurisdiction $k_{j}$ and the profile of residents' types. It is formally defined by $w: \mathcal{Z} \times \mathcal{K}_{J} \times$ $\bar{\Theta} \rightarrow \mathbb{R}$ where $w\left(z, k_{j}, \theta\right):=\sum_{i=1}^{\widetilde{n}(\theta)} v\left(z, \theta_{i}\right)-C\left(z, k_{j}\right)$. Let $w^{*}\left(k_{j}, \theta\right):=\max _{z \in \mathcal{Z}_{\widetilde{n}(\theta)}} w\left(z, k_{j}, \theta\right)$

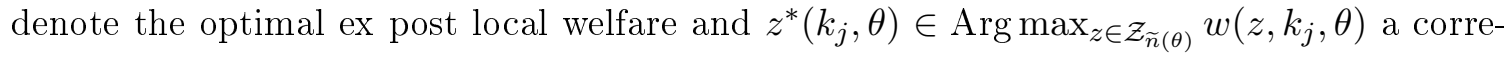
sponding optimal public good mapping function. The following assumption is a congestion hypothesis used to guarantee that it cannot be optimal to have arbitrarily large jurisdictions. ${ }^{12}$

Assumption A 1 The function $w^{*}: \mathcal{K}_{J} \times \bar{\Theta} \rightarrow \mathbb{R}$ is uniformly bounded from above.

\subsection{Some applications}

Example 1: Sharing a natural resource. Citizens are homogenous and each jurisdiction is characterized by $k_{j} \in \mathbb{R}_{+}$where $k_{j}$ corresponds to a limited resource of total value $k_{j}$ which is extracted at no cost and then shared equally among the residents. We have $w^{*}\left(k_{j}, \theta\right)=k_{j}$ if $\widetilde{n}(\theta) \geq 1$ and 0 otherwise.

Example 2: Selecting the number of users of a public good. Consider homogenous jurisdictions each selecting the number of users of the local public good among a set of (homogenous) participants under complete information. Let $C(n)$ denote the cost to serve $n \in \mathbb{N}$ users. The value of the public good for a user is normalized to 1 and we assume that $C$ is convex with $C(1)>1 .^{13}$ We further assume that the average cost per user function $\frac{C(n)}{n}$ is convex with $\lim _{n \rightarrow+\infty} \frac{C(n)}{n}>1$ and is minimized at the mode $n^{*}>1$ with $\frac{C\left(n^{*}\right)}{n^{*}}<1$. Efficiency consists in providing no public good if $n<n_{l}^{*}$, providing the public good to all citizens if $n_{l}^{*} \leq n<n_{u}^{*}$ and providing the public good to only $n_{u}^{*}-1$ citizens if $n \geq n_{u}^{*}$, where $n_{l}^{*}:=\inf \{n \in \mathbb{N} \mid n>C(n)\}$ and $n_{u}^{*}:=\inf \{n \in \mathbb{N} \mid C(n+1)>1+C(n)\}$. Citizens who stay apart enjoy a payoff $\underline{V}>0$ (corresponding to another usage of their time).

Example 3: Competition between exchange platforms. Consider jurisdictions proposing trading platforms designed to exchange multiple units of an homogeneous good.

\footnotetext{
${ }^{11}$ The assumption that $\underline{V}_{k}>0$ reflects the (extra) cost of being put aside once in the jurisdiction.

${ }^{12}$ Participation will be modeled later on, but the intuition as to why A1 implies that too large jurisdictions would run into deficit should be clear given that $w^{*}\left(k_{j}, \theta\right)-\sum_{k=1}^{K} n_{k}(\theta) \cdot \underline{V}_{k}$ goes to $-\infty$ when $\widetilde{n}(\theta)$ goes to $+\infty$.

${ }^{13}$ Our model can deal with situations in which public goods are differentiated by their quality and citizens have private information on how much they value the quality in which case we allow individual preferences to be determined after the location choice in contrast with Rosen's (1974) hedonic price model (see also the discussion on hedonic prices in Konishi (2013)).
} 
To simplify consider that agents are either (unit-demand) buyers characterized by a valuation or (unit-supply) sellers characterized by a production cost. Consider a platform with $n_{B}$ buyers having valuations $v_{1} \geq v_{2} \geq \ldots \geq v_{n_{B}}$ and $n_{S}$ sellers having costs $c_{1} \leq c_{2} \leq \ldots \leq c_{n_{S}}$ and let $n^{*}$ be the largest integer such that $v_{n^{*}} \geq c_{n^{*}}$ (We let $n^{*}=0$ if $v_{1}<c_{1}$ ). If the platform has no friction, then the efficient allocation consists in $n^{*}$ transactions: the buyers with the $n^{*}$ highest valuation buyers purchase one unit of good from the sellers with the $n^{*}$ lowest costs. The welfare is then $\sum_{i=1}^{n^{*}}\left(v_{i}-c_{i}\right)$. For the congestion hypothesis (Assumption A1), we consider that at most $\bar{n}$ transactions can arise in the platform while each (feasible) transaction is costless. For the optimal assignment, we simply have to replace $n^{*}$ above by $\min \left\{n^{*}, \bar{n}\right\}$.

\subsection{The mechanism design setup}

A notable feature of our framework is that citizens may receive extra information regarding their preferences after joining a jurisdiction. It is then natural to allow jurisdictions to elicit these preferences via mechanisms typically not considered in the previous literature on the Tiebout hypothesis. Another distinctive feature of our framework to be detailed later on is that the realization of who joins a jurisdiction is stochastic. Compared to the standard mechanism design literature this calls for defining richer mechanisms that apply no matter how many citizens join the jurisdiction. To simplify the presentation, we assume that jurisdictions post direct deterministic mechanisms such that each citizen $i$ finds it optimal in equilibrium to report his type $\theta_{i}$ truthfully. This is without loss of generality to the extent that jurisdictions cannot post mechanisms that depend on the choice of other jurisdictions (as in Peters and Szentes (2012)). ${ }^{14}$

Formally, a (direct deterministic) mechanism, denoted by $(\widetilde{z}, \widetilde{t}): \bar{\Theta} \rightarrow \mathcal{Z} \times \bigcup_{n \in \mathbb{N}} \mathbb{R}^{n}$, is of the following form. ${ }^{15}$ Each citizen $i$ is asked to report a type $\widehat{\theta}_{i} \in \Theta$. Based on the profile of reports $\widehat{\theta}$, the public $\operatorname{good} \widetilde{z}(\widehat{\theta})$ in $\mathcal{Z}_{\widetilde{n}(\widehat{\theta})}$ is implemented and citizen $i=$ $1, \ldots, \widetilde{n}(\widehat{\theta})$ is requested to pay the tax $\widetilde{t}_{i}(\widehat{\theta})$. Letting $\widetilde{t}(\widehat{\theta}):=\left(\widetilde{t}_{1}(\widehat{\theta}), \cdots, \widetilde{t}_{\widetilde{n}(\widehat{\theta})}(\widehat{\theta})\right)$ denote the profile of taxes in the jurisdiction, the revenue (or budget) of the jurisdiction (with type $\left.k_{j}\right)$ is $\sum_{i=1}^{\widetilde{n}(\widehat{\theta})} t_{i}(\widehat{\theta})-C\left(\widetilde{z}(\widehat{\theta}), k_{j}\right)$. If citizen $i$ 's true type is $\theta_{i}$, his ex post gross payoff is $v\left(\widetilde{z}\left(\widehat{\theta}, \theta_{i}\right)-t_{i}(\widehat{\theta})\right.$. Under truthful reporting (i.e. $\left.\widehat{\theta}=\theta\right)$, we let $\widetilde{u}_{i}\left(m, \theta_{-i}, \theta_{i}\right)$ denote the ex post payoff of citizen $i$. Throughout the analysis, we impose an anonymity constraint stipulating that citizens from the same group should enjoy the same payoff whenever they

\footnotetext{
${ }^{14}$ The reason why it is without loss of generality follows from arguments similar to the so called revelation principle noting that a transformation to a truthful mechanism would not affect the corresponding equilibrium participation profile to be described next. The explicit treatment of stochastic public good choices is also omitted here to alleviate the notation. See Jehiel and Lamy (2015a), our working paper version, for elaborations on this.

${ }^{15}$ We assume implicitly that mechanisms are measurable (i.e. such that the associated payoff functions are measurable) so that all the integrals we consider next are well-defined.
} 
have the same ex post preferences (formally the function $\widetilde{u}_{i}$ does not depend on $i$, and in the sequel we drop the subscript from the notation). ${ }^{16}$ We let $\mathcal{M}$ denote the set of all feasible direct, deterministic, truthful and anonymous mechanisms.

Remark. We have not specified so far whether a citizen joining a jurisdiction could unilaterally decide to stay apart after learning his type, thereby obtaining the (null) payoff that accrues to citizens who are left aside. Whenever such options are available, a feasible mechanism should also ensure that some form of participation constraints is satisfied, the strongest version being that $\widetilde{u}\left(m, \theta_{-i}, \theta_{i}\right) \geq 0$ for any $\theta \in \bar{\Theta}$. Interestingly, as we note later on, our results hold whether or not such additional constraints prevail.

\section{Competitive equilibrium with free mobility}

In our economy, jurisdictions $j \in \mathcal{K}_{J}$ simultaneously post mechanisms $m \in \mathcal{M}$ as described above. Then, a random device $\zeta$ is simultaneously and independently drawn from a uniform distribution on $[0,1]$ for each jurisdiction. The realizations of $\zeta$ are publicly observed by all citizens and participation decisions may depend on these as well as the mechanisms. ${ }^{17}$ The introduction of $\zeta$-which we think is natural from a descriptive viewpoint- is required to ensure that the welfare efficient solution can be decentralized as an equilibrium where jurisdictions use pure and symmetric strategies. Upon observing the profile of mechanisms and the profile of $\zeta$, citizens of the various groups $\mathcal{K}_{C}$ simultaneously decide which jurisdiction to go to. Citizens from the same group are assumed to adopt the same location strategy, and thus any form of coordination (apart from that based on $\zeta$ ) is ruled out at the location stage. Finally, once in a jurisdiction, citizens report their type (we assume truthfulness in equilibrium as explained above).

Poisson distributions. Our large market assumption (we work directly with a continuum of jurisdictions and citizens) coupled with our anonymity restriction leads us to consider that in any jurisdiction the number of citizens from a given group should follow a Poisson distribution. ${ }^{18}$ We let $\mu=\left(\mu_{k}\right)_{k \in \mathcal{K}_{C}} \in \mathbb{R}_{+}^{K}$ refer to a generic profile of Poisson pa-

\footnotetext{
${ }^{16}$ What matters indeed is that citizens expected payoff prior to their location should depend solely on their ex ante group. This anonymity restriction stipulates implicitly that citizens can not be labeled prior to the location stage and use symmetric strategies. See Jehiel and Lamy (2015a) for more details.

${ }^{17}$ Note that $\zeta$ does not enter the utility functions and can be thought of as a public correlation device similar to the one considered in (public) correlated equilibria in game theory (Aumann, 1974) or in sunspot equilibria (Cass and Shell, 1983).

${ }^{18}$ The Poisson model is popular in the search literature (see Rogerson et al.'s (2005) survey or more recently Peters (2010)) and also in the voting literature (Myerson (1998)). The directed search literature (see e.g. Eeckoudt and Kircher, 2010 and Lester, Visschers and Wolthoff (2015)) analyzes also different classes of "matching technologies". While the Poisson distribution has a clear non-cooperative interpretation -it assumes implicitly that entry decisions are made independently (see Jehiel and Lamy (2015b) for elaborations in an auction environment)- other matching technologies require centralized interventions which are typically left unmodeled in that literature.
} 
rameters for each group $k \in \mathcal{K}_{C}$ in a given jurisdiction ( $\mu$ will be endogenously determined in equilibrium). That is, letting $P(N \mid \mu)$ denote the probability that $n(\theta)=N$ when the profile of entry rate is $\mu$, we have $P(N \mid \mu)=e^{-\sum_{k=1}^{K} \mu_{k}} \cdot \prod_{k=1}^{K} \frac{\left[\mu_{k}\right]^{n_{k}}}{n_{k} !} \cdot{ }^{19}$ At the mechanism design stage, we let $g\left(. \mid \mu, k_{j}\right)$ denote the density of the vector of types $\theta$ of the residents in a jurisdiction of type $k_{j} \in \mathcal{K}_{J}$ when the profile of participation rates is $\mu \in \mathbb{R}_{+}^{K}$. By iterated expectation, we have $g\left(\theta \mid \mu, k_{j}\right)=\sum_{\substack{N \in \mathbb{N}^{K}: \\ n(\theta)=N}} P(N \mid \mu) \cdot q\left(\theta \mid N, k_{j}\right)$ where $q\left(\theta \mid N, k_{j}\right)$ has been defined above to denote the density of $\theta$ in a $k_{j}$-jurisdiction with group profile $N$ of citizens.

We let $u_{J}\left(m, k_{j}, \mu\right)$ denote the expected utility of a jurisdiction with type $k_{j}$ having selected the mechanism $m=(\widetilde{z}, \widetilde{t})$ when the profile of participation rate is given by the Poisson distributions $\mu$ and all residents report their type truthfully. When a jurisdiction of type $k_{j}$ seeks to maximize revenue, we have $u_{J}\left(m, k_{j}, \mu\right)=\int_{\bar{\Theta}}\left(\sum_{i=1}^{\widetilde{n}(\theta)} \widetilde{t}_{i}(\theta)-C\left(\widetilde{z}(\theta), k_{j}\right)\right) \cdot g\left(\theta \mid \mu, k_{j}\right) d \theta$. Similarly, we let $u_{k}\left(m, k_{j}, \mu\right)$ denote the expected (ex ante) utility of a citizen from group $k$ in a type $k_{j}$ jurisdiction proposing the direct mechanism $m$ when the distribution of participation is governed by $\mu$ and all citizens report truthfully. We have by iterated expectation

$$
u_{k}\left(m, k_{j}, \mu\right)=\sum_{N \in \mathbb{N} K} P(N \mid \mu) \cdot \int_{Y} \int_{\bar{\Theta}} \int_{\Theta} \widetilde{u}(m, \theta, \widetilde{\theta}) \cdot f_{k}\left(\widetilde{\theta} \mid y, k_{j}\right) d \widetilde{\theta} \prod_{k^{\prime}=1}^{K} \prod_{i_{k^{\prime}}=1}^{n_{k^{\prime}}} f_{k^{\prime}}\left(\theta_{i_{k^{\prime}}}^{\left[k^{\prime}\right]} \mid y, k_{j}\right) d \theta \cdot f_{Y}(y) d y .
$$

Competitive equilibrium is defined as follows.

Definition 1 A competitive equilibrium is defined as a triple of a mechanism profile $m^{*}=$ $\left(m_{k_{j}}^{*}\right)_{k_{j} \in \mathcal{K}_{J}} \in \mathcal{M}^{\mathcal{K}_{J}}$, a payoff profile $\mathcal{V}^{*}=\left(V_{k}\right)_{k \in \mathcal{K}_{C}} \in \mathbb{R}^{K}$ and a participation schedule profile $\mu^{*}=\left(\mu_{k}^{*}\right)_{k \in \mathcal{K}_{C}}$ with $\mu_{k}^{*}: \mathcal{M} \times \mathcal{K}_{J} \times[0,1] \rightarrow \mathbb{R}_{+}$, such that

1. (Utility maximization for jurisdictions) For any $k_{j} \in \mathcal{K}_{j}$,

$$
m_{k_{j}}^{*} \in \operatorname{Arg} \max _{m \in \mathcal{M}} \int_{0}^{1} u_{J}\left(m, k_{j}, \mu^{*}\left(m, k_{j}, \zeta\right)\right) d \zeta
$$

2. (Utility maximization and free mobility of citizens) For any $\left(m, k_{j}, \zeta\right) \in \mathcal{M} \times \mathcal{K}_{J} \times[0,1]$

\footnotetext{
${ }^{19}$ In some applications (e.g. big cities in the role of jurisdictions), one may be concerned by the stochastic nature of the size of jurisdictions resulting from our Poisson specification. Yet, if the expected number of citizens from group $k$ is large in a jurisdiction ( $\mu_{k}$ is large), then the standard deviation in the number of citizens from group $k$ would be equal to $\sqrt{\mu_{k}}$ so that the relative difference in size of similar jurisdictions get small.
} 
and for all $k \in \mathcal{K}_{C},{ }^{20}$

$$
\mu_{k}^{*}\left(m, k_{j}, \zeta\right) \underset{(r e s p .=)}{>} 0 \Rightarrow u_{k}\left(m, k_{j}, \mu^{*}\left(m, k_{j}, \zeta\right)\right) \underset{(\text { resp. } \leq)}{=} V_{k}
$$

3. (Individual rationality and matching conditions) For any $k \in \mathcal{K}_{C}, V_{k} \geq \underline{V}_{k}$ and

$$
V_{k} \underset{(\text { resp. }=)}{>} \underline{V}_{k} \Rightarrow \int_{0}^{1} \sum_{k_{j} \in \mathcal{K}_{J}} \mu_{k}^{*}\left(m_{k_{j}}^{*}, k_{j}, \zeta\right) \cdot f_{J}\left(k_{j}\right) d \zeta \underset{(\text { resp. } \leq)}{=} f_{C}(k) .
$$

Any jurisdiction of type $k_{j}$ chooses its mechanism $m_{k_{j}}^{*}$ before knowing the realizations of $\zeta$. Condition (1) requires that $m_{k_{j}}^{*}$ maximizes the corresponding expected utility with respect to the choice of mechanism taking into account the impact of the mechanism on the participation rates. Condition (2) formalizes the free mobility condition. It says that group $k$ citizens adjust their participation rate to any possible mechanism so that, if the participation rate is positive, citizens of group $k$ get their equilibrium payoff $V_{k}$ in expectation, and, if the participation rate is null, they get a non-larger payoff. Observe that when a given jurisdiction contemplates the impact of a tentative mechanism, it is assumed that the equilibrium utilities of the various group $k$ citizens are unaffected by the mechanism. This is justified by our assumption that each individual jurisdiction is infinitesimal, and it would not be a valid assumption if jurisdictions had market power. In this sense, our utility-taking assumption captures situations with perfect competition between jurisdictions. ${ }^{21}$ Condition (3) ensures that in equilibrium all type $k$ citizens are assigned to at most one jurisdiction and that all type $k$ citizens are assigned to one jurisdiction if their expected payoff is strictly larger than the expected payoff they can derive on their own.

\section{The Main Result}

\subsection{Global first-best}

In our quasi-linear environment, Pareto efficiency reduces to the maximization of the expected global welfare defined as the sum of all citizens' utilities from which the sum of the costs of providing all local public goods should be deducted. For any given profile of (feasible)

\footnotetext{
${ }^{20}$ To alleviate notation, we omit the cases (which could arise with fixed subsidies e.g.) where $u_{k}\left(m, k_{j}, \mu^{*}\left(m, k_{j}, \zeta\right)\right)>V_{k}$ which would imply $\mu_{k}^{*}\left(m, k_{j}, \zeta\right)=+\infty$ but which will run a deficit for the jurisdiction given A1. Our construction is thus as if such mechanisms do not belong to the set $\mathcal{M}$. We also omit the cases where the conditions (2) do not have any solution: if such a case arise out-of-theequilibrium path, let us consider that we do not impose any equilibrium constraint on $\mu$ or equivalently that the corresponding mechanism do not belong to the set $\mathcal{M}$.

${ }^{21}$ Such a discussion appears also in the direct search literature (Guerrieri, Shimer and Wright (2010) and Peters (2010)).
} 
public good functions $z: \mathcal{K}_{J} \times \bar{\Theta} \rightarrow \mathcal{Z}$ and participation rate functions $\mu \in \mathbb{R}_{+}^{\mathcal{K}_{C} \times[0,1] \times \mathcal{K}_{J}}$, let $G W(\widetilde{z}, \mu)$ denote the associated expected global welfare defined as

$$
\begin{aligned}
G W(z, \mu):=\sum_{k_{j} \in \mathcal{K}_{J}} \int_{0}^{1}\left[\int_{\bar{\Theta}} w\left(z\left(k_{j}, \theta\right), k_{j}, \theta\right) \cdot g\left(\theta \mid \mu\left(\zeta, k_{j}\right), k_{j}\right) d \theta\right] \cdot f_{J}\left(k_{j}\right) d \zeta \\
+\sum_{k=1}^{K}\left[f_{C}(k)-\sum_{k_{j} \in \mathcal{K}_{J}} \int_{0}^{1} \mu_{k}\left(\zeta, k_{j}\right) \cdot f_{J}\left(k_{j}\right) d \zeta\right] \cdot \underline{V}_{k} .
\end{aligned}
$$

The welfare-maximizing solution, which is referred to as the global first best, seeks to maximize $G W(z, \mu)$ subject to the matching constraint that every citizen whatever his group $k$ can belong to at most one jurisdiction. Clearly, for any participation profile $\mu$, welfare maximization requires any jurisdiction of type $k_{j}$ to pick a mechanism that implements the efficient public good $z^{*}\left(k_{j}, \theta\right)$ for every taste profile $\theta$ of its constituency. Seeking for the global first-best then boils down to finding an efficient profile of participation in jurisdictions posting ex post efficient mechanisms, i.e. a solution to the following program (see the Online Appendix for existence):

$$
\max _{\widehat{\mu} \in \mathbb{R}_{+}^{\mathcal{K}_{C} \times[0,1] \times \mathcal{K}_{J}}} G W\left(z^{*}, \widehat{\mu}\right) \quad \text { s.t. } \sum_{k_{j} \in \mathcal{K}_{J}} \int_{0}^{1} \widehat{\mu}_{k}\left(\zeta, k_{j}\right) \cdot f_{J}\left(k_{j}\right) d \zeta \leq f_{C}(k), \forall k \in \mathcal{K}_{C} .
$$

For a given profile of utilities $V=\left(V_{k}\right)_{k \in \mathcal{K}_{C}}$, a given profile of participation rates $\mu=$ $\left(\mu_{k}\right)_{k \in \mathcal{K}_{C}}$, a given public good function $\widetilde{z}: \bar{\Theta} \rightarrow \mathcal{Z}$, a given jurisdiction of type $k_{j} \in \mathcal{K}_{j}$, the net local welfare (i.e., net of the opportunity costs of the participating citizens) is defined as: ${ }^{22}$

$$
N L W\left(\widetilde{z}, k_{j}, \mu ; V\right)=\int_{\bar{\Theta}} w\left(\widetilde{z}(\theta), k_{j}, \theta\right) \cdot g\left(\theta \mid \mu, k_{j}\right) d \theta-\sum_{k=1}^{K} \mu_{k} \cdot V_{k}
$$

Calling $\lambda=\left(\lambda_{k}\right)_{k \in \mathcal{K}_{C}} \in \mathbb{R}_{+}^{K}$ the vector of the Lagrange multipliers $\lambda_{k}$ associated to the matching inequalities, the Lagrangian associated to program (6) can be written as:

$$
\mathcal{L}(\widehat{\mu}, \lambda)=\sum_{k_{j} \in \mathcal{K}_{J}} \int_{0}^{1} N L W\left(z_{k_{j}}^{*}, k_{j}, \widehat{\mu}\left(\zeta, k_{j}\right) ;\left(\lambda_{k}+\underline{V}_{k}\right)_{k \in \mathcal{K}_{C}}\right) \cdot f_{J}\left(k_{j}\right) d \zeta+\sum_{k=1}^{K} f_{C}(k) \cdot\left(\lambda_{k}+\underline{V}_{k}\right)
$$

where $z_{k_{j}}^{*}$ denotes the function $z^{*}\left(k_{j},.\right)$. The first-order conditions w.r.t. $\widehat{\mu}_{k}$ associated to the maximization of $\mathcal{L}$ implies that at any optimum $\left(\widehat{\mu}^{o p t}, \lambda^{o p t}\right)$, and for any $k_{j} \in \mathcal{K}_{J}$ and $\zeta \in[0,1], \widehat{\mu}^{o p t}\left(k_{j}, \zeta\right)$ should belong to the set $\operatorname{Argmax}_{\mu \in \mathbb{R}_{+}^{\mathcal{K}_{C}}} N L W\left(z_{k_{j}}^{*}, k_{j}, \mu ; \lambda^{\text {opt }}+\underline{V}\right)$ which is included in the set of $\mu \in \mathbb{R}_{+}^{\mathcal{K}_{C}}$ such that for all $k \in \mathcal{K}_{C}$ :

$$
\frac{\partial N L W\left(z_{k_{j}}^{*}, k_{j}, \mu ; \lambda^{o p t}+\underline{V}\right)}{\partial \mu_{k}} \underset{(\text { resp. } \leq)}{=} 0 \text { if } \mu_{k} \underset{(\text { resp }=)}{>} 0
$$

\footnotetext{
${ }^{22}$ Remember that $\mu_{k}$ is the expected number of citizens of type $k$ in the corresponding Poisson distribution.
} 
and for any $k \in \mathcal{K}_{C}, \sum_{k_{j} \in \mathcal{K}_{J}} \int_{0}^{1} \widehat{\mu}_{k}^{o p t}\left(\zeta, k_{j}\right) \cdot f_{J}\left(k_{j}\right) d \zeta \leq f_{C}(k)$ if $\lambda_{k}^{o p t}=0$. Clearly, $\lambda_{k}^{o p t}+\underline{V}_{k}$ can be interpreted as the marginal welfare gain brought by an extra citizen of type $k$.

Example 2 (continued): In the user selection example, let us assume that $\underline{V}$ is small enough such that jurisdictions with an intermediary value of $\mu$ can contribute positively to the global welfare (formally, $\operatorname{Argmax}_{\mu \geq 0} N L W\left(z^{*}, \mu ; \underline{V}\right)>0$ ). By contrast, when participation is either too small or too large in a jurisdiction, the associated net local welfare is negative. If the mass of jurisdictions is large compared to the mass of citizens, the optimum consists then in splitting citizens uniformly on a subset of the jurisdictions and leaving the other ones empty so that citizens get strictly more than $\underline{V} \cdot{ }^{23}$

\subsection{The pivot mechanism}

For a given type $k_{j}$ of jurisdiction, the pivot mechanism that we denote by $m_{k_{j}}^{p i v}=$ $\left(\widetilde{z}_{k_{j}}^{p i v}, \widetilde{t}_{k_{j}}^{p i v}\right)$ is defined by the efficient allocation rule $\widetilde{z}_{k_{j}}^{p i v}(\theta)=z^{*}\left(k_{j}, \theta\right)$ for each $\theta \in \bar{\Theta}$ and the requirement that each citizen $i$ pays a transfer equal to the welfare loss that his presence imposes on others, i.e. $\left[\widetilde{t}_{k_{j}}^{p i v}(\theta)\right]_{i}=w^{*}\left(k_{j}, \theta_{-i}\right)-\left[w^{*}\left(k_{j}, \theta\right)-v\left(z^{*}\left(k_{j}, \theta\right), \theta_{i}\right)\right]$. A fundamental property of the pivot mechanism is that the payoff of each citizen is equal to the net welfare contribution he brings to the jurisdiction. That is, for each $\theta \in \bar{\Theta}$ and $k_{j} \in \mathcal{K}_{J}$, we have

$$
\widetilde{u}\left(m_{k_{j}}^{p i v}, \theta_{-i}, \theta_{i}\right)=w^{*}\left(k_{j}, \theta\right)-w^{*}\left(k_{j}, \theta_{-i}\right)
$$

The pivot mechanism belongs to the class of Groves mechanism (Groves, 1973) and it is thus a weakly dominant strategy for each citizen to report truthfully his type (formally, $\widetilde{u}\left(m_{k_{j}}^{p i v}, \theta_{-i}, \theta_{i}\right) \geq v\left(\widetilde{z}_{k_{j}}^{p i v}\left(\theta_{-i} \cup \widehat{\theta}_{i}\right), \theta_{i}\right)-\left[t_{k_{j}}^{p i v}\right]_{i}\left(\theta_{-i} \cup \widehat{\theta}_{i}\right)$ for any $\left.\widehat{\theta}_{i} \in \Theta\right)$. If two citizens have the same preferences, then (10) implies that they should enjoy the same payoff ensuring that our anonymity condition is satisfied. To sum up, $m_{k_{j}}^{p i v} \in \mathcal{M}$. Furthermore, since we have assumed that jurisdictions can exclude whoever they wish, any extra citizen can only increase the local welfare. Thus given (10), participation constraints even at the ex post stage are automatically satisfied. ${ }^{24}$

Example 3 (continued): For a realization of the type of the entrants such that $n^{*} \leq \bar{n}$, the pivot mechanism is characterized by the $n^{*}$ buyers with the highest valuations who each buy one unit at price $\max \left\{v_{n^{*}+1}, c_{n^{*}}\right\}$ and by the $n^{*}$ sellers with the lowest costs who each sell one unit at price $\min \left\{v_{n^{*}}, c_{n^{*}+1}\right\}$. The revenue of the platform is then $n^{*} \cdot\left[\max \left\{v_{n^{*}+1}, c_{n^{*}}\right\}-\right.$ $\left.\min \left\{v_{n^{*}}, c_{n^{*}+1}\right\}\right] \leq 0$. The inequality is obtained by noting that $n^{*}$ is such that $v_{n^{*}} \geq c_{n^{*}}$ and $v_{n^{*}+1}<c_{n^{*}+1}$. We see that the pivot mechanism runs some deficit except when the

\footnotetext{
${ }^{23}$ See Jehiel and Lamy (2015a) for details.

${ }^{24}$ Formally, $\mathcal{Z}_{n} \supset \mathcal{Z}_{n-1}$ implies that $w^{*}\left(k_{j}, \theta\right) \geq w^{*}\left(k_{j}, \theta_{-i}\right)$ which further implies that $\widetilde{u}\left(m_{k_{j}}^{p i v}, \theta_{-i}, \theta_{i}\right) \geq$ 0 , namely the participation constraints are satisfied ex post.
} 
congestion constraint is binding $\left(n^{*}>\bar{n}\right)$ in which case the revenue can be expressed as $\bar{n} \cdot\left[\max \left\{v_{\bar{n}+1}, c_{\bar{n}}\right\}-\min \left\{v_{\bar{n}}, c_{\bar{n}+1}\right\}\right]-$ an expression that is typically positive.

\subsection{The Main Decentralization Result}

Theorem 1 Assume the congestion condition A1 holds. When jurisdictions are revenuemaximizers, there is a competitive equilibrium in which all jurisdictions post the pivot mechanism and the global first-best is achieved.

The proof of the Theorem consists in building an equilibrium based on the optimal solution $\left(\widehat{\mu}^{\text {opt }}, \lambda^{\text {opt }}\right.$ ) of the Lagrangian where the Lagrange multiplier $\lambda_{k}^{o p t} \geq 0$ augmented by the reservation utility $\underline{V}_{k}$ of group $k$ citizens is identified with the equilibrium utility $V_{k}$ of group $k$ citizens. To this end, observe first (as a simple accounting insight given eq. (3)) that in a competitive equilibrium where the equilibrium utility of a group $k$ citizen is $V_{k}$, the expected revenue of a $k_{j}$ jurisdiction when she posts the mechanism $m \in \mathcal{M}$ is equal to the net local welfare:

$$
\int_{0}^{1} u_{J}\left(m=(\widetilde{z}, \widetilde{t}), k_{j}, \mu^{*}\left(m, k_{j}, \zeta\right)\right) d \zeta=\int_{0}^{1} N L W\left(\widetilde{z}, k_{j}, \mu^{*}\left(m, k_{j}, \zeta\right) ; \mathcal{V}^{*}\right) d \zeta
$$

where $\mathcal{V}^{*}=\left(V_{k}\right)_{k \in \mathcal{K}_{C}}$. Given that the expected net local welfare is maximized at the global first-best (eq. 9), in order to establish that posting the pivot is optimal for jurisdictions it is enough to show that if jurisdictions choose the pivot mechanism they can achieve the payoff $\int_{0}^{1} N L W\left(z_{k_{j}}^{*}, k_{j}, \widehat{\mu}^{o p t}\left(\zeta, k_{j}\right) ; \mathcal{V}^{*}\right) d \zeta$, or equivalently that it is an equilibrium for citizens to participate according to the $\widehat{\mu}^{o p t}$ Poisson distribution when jurisdictions post the pivot mechanism. The latter condition follows from the fundamental property of the pivot mechanism that the contribution of each citizen to the local welfare corresponds to his payoff (eq. 10), which in the Poisson model translates into:

$$
\frac{\partial N L W\left(z_{k_{j}}^{*}, k_{j}, \mu ; \mathcal{V}^{*}\right)}{\partial \mu_{k}}=u_{k}\left(m_{k_{j}}^{p i v}, k_{j}, \mu\right)-V_{k}
$$

From eq. (9), the optimality conditions imply the free mobility conditions (3) in Definition 1, thereby establishing the Theorem.

To understand the optimality of the participation rates in the pivot mechanism from a more intuitive viewpoint, consider the social planner who wants to maximize welfare, and hold fixed the (optimal) participation rates for all but one jurisdiction $j$. Thus, the outside options $V_{k}$ of group $k$ citizens are fixed. For the participation rates to be optimally set in jurisdiction $j$, it should be that the marginal change in expected local welfare from having another group $k$ citizen move to the jurisdiction coincide with the outside option $V_{k}$ (assuming there are possibly some group $k$ citizens in jurisdiction $j$ ). Connecting this back 
to the pivot mechanism, the surplus a citizen is getting from participating is exactly his contribution to the local welfare, so that citizens' incentives to move to jurisdiction $j$ look just like the planner's, thereby yielding the desired optimality condition.

Several comments about the derivation of Theorem 1 are in order. First, an important feature that was used in the argument is that the ex ante utility is the same for all citizens of the same group, which forbids any form of asymmetric coordination in the participation strategies used by citizens of the same group. ${ }^{25}$ Second, our arguments (in particular the two key steps (11) and (12)) hold irrespective of whether there is correlation in citizens' preferences (even conditional on the public signals), irrespective of whether citizens receive additional information about their fellow citizens, and irrespective of whether citizens have private information ex ante (the group $k$ to which a citizen belongs need not be commonly observed). ${ }^{26}$ Third, our result does not guarantee that all competitive equilibria must be first-best efficient. ${ }^{27}$ This potential multiplicity suggests a role for the federal government in coordinating agents on the efficient participation equilibrium. Fourth, in our competitive equilibrium, jurisdictions may make positive profit, in contrast with most of the GE approaches to the Tiebout hypothesis: Intuitively, this will happen when there is scarcity in the mass of jurisdictions with favorable production facilities. ${ }^{28}$

Our decentralization result can be viewed as generalizing the observation made in the competing auction literature that sellers find it optimal to post second-price auctions with reserve prices set at their valuations, since such auction formats correspond to pivot mechanisms in the simple context of one object auctions (see McAfee (1993), Peters (1997, 2001)). ${ }^{29}$ The insight obtained in the competing auction literature has also been used in the directed search literature interested in the wage determination in firm/worker matching contexts, generally suggesting simple wage setting mechanisms that would be payoff-equivalent

\footnotetext{
${ }^{25}$ Sequential entry would invalidate the conclusion of Theorem 1. For general matching technologies but ruling out the possibility of ex ante asymmetric information, Lester et al. (2015) show that the pivot mechanism should be augmented by fees/subsidies designed to internalize the matching externalities. It should be mentioned that such fees may sometimes lead to violations of the participation constraints.

${ }^{26}$ The possibility that citizens have ex ante private information makes it non-trivial that efficiency would arise in equilibrium. This should be contrasted with the symmetric information scenario in which case efficiency can always been expected to be achieved through the use of judicious fees (see Levin and Smith (1994) and Lester et al. (2015) for related discussions in the symmetric information case).

${ }^{27}$ More precisely, when all jurisdictions post the pivot mechanism in the context of Example 2 with a large relative mass of jurisdictions, there would be one participation equilibrium with too many occupied jurisdictions in which citizens' equilibrium utilities go down to $\underline{V}$, which is not the optimum as discussed above. Whether by a judicious choice of size-dependent taxes/subsidies, jurisdictions can force the efficient equilibrium is left for future research.

${ }^{28}$ The idea that one could gain by undercutting a tentative positive-profit mechanism does not apply here because such an undercutting by affecting the participation rates need not be profitable. This is in contrast with most of the previous literature on the Tiebout hypothesis with the exception of Epple and Zelenitz (1981).

${ }^{29}$ See Levin and Smith (1994) and Jehiel and Lamy (2015b) for environments with a single auction but where potential participants have participation/opportunity costs which can be viewed as a reduced form for competitive environments.
} 
to the second-price auction. ${ }^{30}$ To the best of our knowledge, that literature has not considered the case of multiple hires with potential complementarities between workers. Our result in that application suggests the use of more complex wage setting mechanisms in which the wage of a worker would depend on the reported characteristics of his fellow workers (through the pivot mechanism formula).

It should be stressed that in contrast to the auction setting, our framework requires the use of public random devices $\zeta$ insofar as it need not be optimal to spread ex ante similar citizens uniformly over similar jurisdictions when there are too many of them and there are economies of scale associated with the local public goods. ${ }^{31}$ Interestingly, in the equilibrium constructed in Appendix to prove Theorem 1, all type $k_{j}$ jurisdictions make the same expected profit irrespective of $\zeta$, which allows us to reinterpret the equilibrium of the Theorem as one in which there is no public device $\zeta$, but jurisdictions post $\zeta$ in addition to the mechanism $m_{k_{j}}^{p i v}$. In particular, when some $k_{j}$ jurisdictions are always empty at the optimum, it implies that the expected revenue of non-empty $k_{j}$ jurisdictions is also zero in the equilibrium supporting the global first-best. ${ }^{32}$

Contribution to the mechanism design literature: An interesting by-product of our analysis is that the equilibrium shown to decentralize the first best is such that local budgets are ex ante balanced (given that jurisdictions have the option to propose the default mechanism $m^{0}$ consisting in providing no public good (i.e. $z \in \mathcal{Z}_{0}$ ) and charging no tax which obviously guarantees null revenues). This observation together with the observations that public decisions are ex post efficient and citizens' individual participation constraints are satisfied in the pivot mechanism seems at odds with the vast literature that has followed the introduction of the VCG mechanism and which has found in the vein of Myerson and Satterthwaite (1983) that it was impossible to satisfy simultaneously ex post efficiency, individual participation constraints and budget balancedness in contexts with fixed sets of participants. ${ }^{33}$ Of course, a key difference is that the set of participants is endogenous

\footnotetext{
${ }^{30}$ Julien, Kennes and King (2000) and Shimer (2005) consider workers making wage offer to firms, i.e. a first-price auction setup. Kim and Kircher (2015) extends this insight in environments where the sellers/firms reservation values are private information, where they can not make reserve price commitment but can only use cheap talk. Lester et al. (2016) consider environments where there are participation cost after the matching occurs: we conjecture that the dynamic mechanism they consider is payoff-equivalent to the generalized version of the pivot mechanism for such dynamic environments, i.e. that bidders pay the expected externality they impose by their presence.

${ }^{31}$ See the detailed treatment of Example 2 in Jehiel and Lamy (2015a).

${ }^{32}$ This can be viewed as formalizing an insight discussed in the context of contestable markets in IO stipulating that the pressure from potential non-present rivals may drive profits down to zero (see Baumol, Panzar and Willig (1982)).

${ }^{33}$ Possibility results can sometimes be obtained in multilateral trading environments in which there is a sufficient imbalance between the number of sellers and buyers, and when the supports of buyers and sellers' valuations are not identical (see Williams (1999) for the derivation of such insights). We note that the mechanism used to show this is not the pivot mechanism as defined in subsection 4.2 but rather the VCG mechanism in which the participation constraints of the lowest valuation buyer and lowest cost seller are
} 
in our setting, and our congestion assumption A1 (together with our maintained symmetry assumption) forces the equilibrium utilities of agents to be fixed independently of the chosen mechanism. As it turns out, considering the exchange platform application in Example 3, if there were no congestion, the pivot mechanism would lead to budget deficits for any given set of entrants (this is fundamentally why the inefficiency result of Myerson and Satterthwaite holds as shown by Williams (1999)). But, our congestion assumption captured through the capacity constraint $\bar{n}$ of platforms changes the picture. As we have noted, whenever the number of sellers and buyers exceed the capacity constraint $\bar{n}$, the pivot mechanism may run budget surpluses. In the optimum, one must reach the point in which the capacity constraints of platforms are sufficiently binding, as otherwise concentrating the exchanges on a smaller number of platforms (by increasing the participation rates in those platforms) would be welfare-enhancing (it would increase the possibility and numbers of efficient trades). At such optimal levels of participation, the pivot mechanism must run budget surpluses, as implied by our analysis.

A second observation is that in contrast with the literature on budget-balanced mechanisms initiated by d'Aspremont and Gerard-Varet (1979), full efficiency does not require that the budget be entirely distributed to citizens, and jurisdictions play the role of residual claimants (see however the discussion of robustness in Section 5). Had we forced jurisdictions to distribute the entire budget surplus to the local residents, then some inefficiencies would be inevitable (see Section 5 on other local objectives for an illustration of this).

A final observation is that the mechanism design literature with exogenous participation has had a hard time dealing with multidimensional information ${ }^{34}$ and it has suggested that if private information is correlated across agents, a designer can easily extract the full surplus if the exact shape of the correlation is available to the designer (Crémer and McLean (1988)). By contrast, our analysis reveals that when there is competition across designers/jurisdictions and when participation is endogenous, then in our equilibrium the chosen mechanisms do not depend on the information structure at all and they always correspond to the pivot mechanism, in particular having a robust mechanism design flavor addressing Wilson's (1987) critique.

binding. Such a VCG mechanism coincides with the pivot mechanism when agents' valuation supports are identical, but not otherwise (as noted at the end of subsection 4.2, the pivot mechanism always runs deficits when there is no congestion).

${ }^{34}$ Difficulties arise already in the multi-product monopoly case (Rochet and Choné (1998)). 


\section{Conclusion: Robustness, limitations, and extensions}

Robustness. In our quasi-linear environment, the decentralization result continues to hold if the revenues of jurisdictions are split among agents independently of their location according to some pre-defined ownership structure as in GE models. This is so because there is no wealth effects on citizens' incentives in our quasi linear economy. Note also from (11) that the expected revenue of a jurisdiction coincides with her marginal contribution to the global welfare. This implies that if jurisdictions can make pre-investments affecting their cost structure before interaction takes place, then efficiency can be extended to include the determination of these, thereby broadening the scope of Theorem $1 .{ }^{35}$ Our result also extends to the case in which the types of jurisdictions are private information, as long as the type $k_{j}$ of the jurisdiction does not affect the distribution of citizens' types (see Jehiel and Lamy (2014) for formal details in the context of single object auctions). Finally, the decentralization result extends to the scenario in which some characteristics of citizens are publicly observed and both jurisdictions' cost function and citizens' preferences function are directly affected by the public characteristics of the non-excluded citizens. ${ }^{36}$ If excluded citizens (either their number or additional observable characteristic) enter the welfare, ${ }^{37}$ then the externality they impose by their mere presence is no longer null which could result in the violation of participation constraints. Similarly, if, in addition, the public characteristics of a citizen were to influence the distribution of citizens' types in the jurisdiction, then the pivot mechanism should be augmented by fees that depend on these characteristics in a way that would allow the citizens to internalize the resulting externalities and it could also result in the violation of participation constraints.

Other local objectives. Various objectives other than revenues can be considered. One natural idea would be to require that the revenues of taxes of jurisdictions be entirely distributed to the citizens of the jurisdiction. We note that in this case inefficiencies may inevitably arise. For example, in the context of the natural resource sharing example (see Example 1), this would lead jurisdictions whatever their amount of natural resources to impose no tax, so that jurisdictions with high amount of natural resources would be too large as compared with the first-best insofar as citizens would not internalize the negative externality they impose on their fellow citizens. Another idea would be that jurisdictions seek to maximize some form of local welfare. It is not straightforward how to define local

\footnotetext{
${ }^{35}$ A similar observation appears in Albrecht et al. (2014) in the context of single object auctions.

${ }^{36}$ Such extensions may be valuable for the modeling of school assignment problems. In Jehiel and Lamy (2015a), we formalize such externalities by including a specification of the observable characteristics in the public good $z$, and thus the set of feasible public goods depends on the profile of observable characteristics of non-excluded citizens.

${ }^{37}$ E.g. it could be costly to exclude citizens and the associated cost could depend on the quality of the public good.
} 
welfare given that the constituency is endogenously shaped by the choice of mechanism. Assuming jurisdictions seek to maximize the welfare of those citizens who join in equilibrium, the objective can either be the total local welfare or the per capita welfare. In either case, inefficiencies are shown to arise in the context of the natural resource example (see Jehiel and Lamy (2015a)). We conclude that if jurisdictions seek to maximize objectives other than revenues including some forms of local welfare, it is unlikely that they will be incentivized to post the pivot mechanism and thus that the decentralization result of Theorem 1 would hold..$^{38}$

The mobility framework. Our analysis assumes that all citizens can freely choose their jurisdictions to start with and it does not consider scenarios in which citizens once located could decide to re-locate (relocation costs are implicitly assumed to be too high). As a natural follow-up, one may adopt a richer perspective in which citizens could be heterogeneous in their re-location costs. While a full-fledged dynamic analysis of this goes beyond the scope of this paper, a simple stylized case can be considered. Suppose that some citizens are freely mobile as in the main model while others are stuck to their location. If jurisdictions were to post the pivot mechanism, it would be an equilibrium for mobile citizens to sort into the various jurisdictions in a welfare-efficient way. ${ }^{39}$ However, if jurisdictions seek to maximize revenues then in an attempt to reduce the rents of the non-mobile citizens (which unlike those of mobile citizens depend on the choice of mechanism), jurisdictions would choose to distort the choice of the allocation rule, typically by providing less public good than is socially desirable. ${ }^{40}$ A simple fix to restore efficiency can be proposed. Suppose jurisdictions are instructed to maximize local revenues augmented with the welfare of the local non-mobile residents (such an objective may be the result of the non-mobile residents enjoying all the property rights of the jurisdiction). It is readily verified that the local objective then boils down to the local welfare net of the utilities of the mobile citizens. The same logic as that developed in the main model would allow us to conclude that the first-best can be decentralized as an equilibrium in which jurisdictions post the pivot mechanism.

Multiple public good jurisdictions. Our model assumes that a single entity determines all locally provided public goods and their pricing. Taking into account that there are different types of local public goods (schooling, transportation, parks, museums), it would seem natural to explore scenarios in which each public good would be provided by

\footnotetext{
${ }^{38}$ Hatfield, Kojima and Kominers (2015) show that any mechanism that gives efficient incentives in terms of pre-participation private investments should correspond to the pivot mechanism. Given that entry decisions can be viewed as a pre-participation investment, we conjecture that any general decentralization result should rely on the pivot mechanism or some payoff-equivalent mechanism.

${ }^{39}$ Formally, (12) still holds with non-mobile citizens such that welfare maximizing entry profiles are equilibrium profiles.

${ }^{40}$ This follows from the observation that inefficiencies would typically arise in optimal mechanisms with exogenous participation as in Myerson (1981).
} 
a separate body. If public goods are managed independently of each other, inefficiencies are to be expected when public good managers seek to maximize revenues. The reason for the inefficiencies is that there is a free-riding problem between the managers concerning the determination of the common constituency. In a competing auction environment (with multiple sellers per jurisdiction), this would tilt sellers' incentives toward Myerson's (1981) optimal reserve prices. A preliminary analysis of this in the context of public goods appears in Jehiel and Lamy (2015a) suggesting that the free-riding is affected by the number of public goods, the elasticity as well as the curvature of the local welfare with respect to the participation rate, and how private information is distributed. Clearly this should be the subject of further work. ${ }^{41}$

Local versus global public goods. In our economy, there is no interaction between jurisdictions once citizens are located. We conjecture that our results could be extended to situations in which private goods are exchanged between economic agents across jurisdictions. However, coping with situations in which citizens could benefit from local public goods provided elsewhere (spillover effects) or with situations with global public goods that would be provided locally (such as carbon emissions) would require further investigation. In particular it would be interesting to investigate whether bargaining between jurisdictions could eliminate the potential inefficiencies resulting from the associated externalities (this would parallel the question addressed by Jehiel (1997) yet allowing for much more general competitive environments).

Beyond quasi-linearity and private values. It is well-known from Gibbard (1973) and Satterthwaite (1975) that outside the quasi-linear environment, there is little hope to implement efficient social choice rules in the presence of asymmetric information at least in a robust way (i.e, relying on dominant strategy). This is the reason why we maintained the quasi-linearity assumption by contrast with the GE literature on the Tiebout hypothesis. Moving in the direction of interdependent preferences, Jehiel and Moldovanu (2001)'s impossibility result gives little hope for the extension of our decentralization result outside the private value setting even maintaining the quasi-linearity assumption.

Relaxing jurisdictions' commitment power and citizens' rationality. Our analysis assumes that jurisdictions commit to their mechanisms at an ex ante stage. Without such a commitment power, jurisdictions would have an incentive to distort their mecha-

\footnotetext{
${ }^{41} \mathrm{An}$ interesting avenue for future research is to analyze how jurisdictions can alleviate the inefficiencies in multiple public good provider environments. An illustration of this is provided by auction houses (in the role of jurisdictions) that typically try to deter sellers (in the role of public good providers) from posting reserve prices above their valuation. Engelbrecht-Wiggans and Sonnenmacher (1999) discuss what is considered nowadays by historians as one of the main explanations for the spectacular development of the Port of NewYork in the early nineteenth century: drastic institutional changes in the design of auctions for imported goods. Several innovations in the auction law (regarding taxation) in New-York encouraged sellers to lower their reserve price.
} 
nisms after the location decisions, invalidating the decentralization result and calling for some form of regulation. ${ }^{42}$ Our analysis also assumes that citizens' location decisions are made rationally based on the correct inference regarding the link of the posted mechanism and the location decisions of other citizens. It would be interesting to relax this assumption, e.g. as it would alter the working of the fiscal competition between jurisdictions, as illustrated in a competing auction environment by Jehiel and Lamy (2015c) who use the machinery of Jehiel (2005).

\section{Appendix: Proof of Theorem 1}

Let $\left(\widehat{\mu}^{o p t}, \lambda^{o p t}\right) \in \mathbb{R}_{+}^{\mathcal{K}_{C} \times[0,1] \times \mathcal{K}_{J}} \times \mathbb{R}_{+}^{K}$ denote a solution of the Lagrangian of the maximization program (6). Note that the inequality $\lambda_{k}^{o p t} \geq 0$ stands as an equality when the corresponding matching condition for group $k$ in (6) stands as an inequality. We now build a competitive equilibrium where each jurisdiction posts the pivot mechanism (i.e. $m_{k_{j}}^{*}=m_{k_{j}}^{p i v}$ ), where group $k$ citizens expected payoff is equal to the associated Lagrange multiplier at the optimum augmented by their reservation utility (i.e. $\mathcal{V}_{k}^{*}=\lambda_{k}^{o p t}+\underline{V}_{k}$ ), where the equilibrium entry rates at the pivot mechanism match those at the optimum (i.e. $\left.\mu^{*}\left(m_{k_{j}}^{p i v}, k_{j}, \zeta\right)=\widehat{\mu}^{o p t}\left(\zeta, k_{j}\right)\right)$, and last for any other mechanisms $m \in \mathcal{M}$ the entry profile is specified such that the equilibrium conditions (3) are satisfied (if a solution to the equations (3) exists, otherwise we set $\mu^{*}\left(m, k_{j}, \zeta\right)=(0, \cdots, 0)$ for any $\left.\zeta \in[0,1]\right)$.

When jurisdictions are revenue-maximizers, the expected welfare in a jurisdiction corresponds to the sum of all agents' expected rents, namely $\int_{\bar{\Theta}} w\left(\widetilde{z}_{k_{j}}(\theta), k_{j}, \theta\right) \cdot g\left(\theta \mid \mu, k_{j}\right) d \theta=$ $u_{J}\left(m, k_{j}, \mu\right)+\sum_{k=1}^{K} \mu_{k} \cdot u_{k}\left(m, k_{j}, \mu\right) .{ }^{43}$ Then by integrating w.r.t. $\zeta$ and for our equilibrium entry rates, we obtain that for any type $k_{j}$ jurisdiction and any mechanism $m=(\widetilde{z}, \widetilde{t}) \in \mathcal{M}$

$$
\begin{aligned}
\int_{0}^{1} u_{J}\left(m, k_{j}, \mu^{*}\left(m, k_{j}, \zeta\right)\right) d \zeta & =\int_{0}^{1}\left(\int_{\bar{\Theta}} w\left(\tilde{z}_{k_{j}}(\theta), k_{j}, \theta\right) \cdot g\left(\theta \mid \mu^{*}\left(m, k_{j}, \zeta\right), k_{j}\right) d \theta\right) d \zeta-\sum_{k=1}^{K} \int_{0}^{1} \mu_{k}^{*}\left(m, k_{j}, \zeta\right) \cdot u_{k}\left(m, k_{j}, \mu^{*}\left(m, k_{j}, \zeta\right)\right) d \zeta \\
& =\int_{0}^{1}\left(\int_{\bar{\Theta}} w\left(\tilde{z}_{k_{j}}(\theta), k_{j}, \theta\right) \cdot g\left(\theta \mid \mu^{*}\left(m, k_{j}, \zeta\right), k_{j}\right) d \theta\right) d \zeta-\sum_{k=1}^{K}\left[\int_{0}^{1} \mu_{k}^{*}\left(m, k_{j}, \zeta\right) d \zeta\right] \cdot V_{k},
\end{aligned}
$$

where the last equality comes from the equilibrium equations (3) (or alternatively $\mu^{*}\left(m, k_{j}, \zeta\right)=$ $(0, \cdots, 0)$ for any $\zeta \in[0,1]$ if no such solutions exist). To sum up, we obtain (11) and the revenue of type $k_{j}$ jurisdictions is thus bounded by $\operatorname{Arg} \max _{\mu \in \mathbb{R}_{+}^{K}} N L W\left(z_{k_{j}}^{*}, k_{j}, \mu ; \mathcal{V}^{*}\right)$. Furthermore, this bound (which does not depend on $\zeta$ ) is attained for the pivot mechanism and for any realization of $\zeta$ since $\mu^{*}\left(m_{k_{j}}^{\text {piv }}, k_{j}, \zeta\right)=\widehat{\mu}^{\text {opt }}\left(\zeta, k_{j}\right) \in \operatorname{Arg} \max _{\mu \in \mathbb{R}_{+}^{K}} N L W\left(z_{k_{j}}^{*}, k_{j}, \mu ; \lambda^{\text {opt }}+\underline{V}\right)$ and since $\mathcal{V}^{*}=\lambda^{o p t}+\underline{V}$. We conclude that jurisdictions find it optimal to post pivot mech-

\footnotetext{
${ }^{42}$ See Lamy (2013) for the derivation of such a hold-up problem in auctions with endogenous entry.

${ }^{43} \mathrm{We}$ do not allow jurisdictions to burn money. If they could, then the local net welfare will be an upperbound of the seller's revenue and it would not change our argument.
} 
anisms. ${ }^{44}$

What remains to be shown is that the entry rates $\widehat{\mu}^{o p t}\left(\zeta, k_{j}\right)$ are equilibrium profiles in the pivot mechanism $m_{k_{j}}^{p i v}$. For this we establish (12). For any vector $N \in \mathbb{N}^{K}$, let $N_{-k}=\left(n_{1}, \ldots, n_{k-1}, n_{k}-1, n_{k+1}, \ldots, n_{K}\right)$. Similarly we let $N_{+k}=\left(n_{1}, \ldots, n_{k-1}, n_{k}+\right.$ $\left.1, n_{k+1}, \ldots, n_{K}\right)$. As a preliminary, note that $\frac{\partial P(N \mid \mu)}{\partial \mu_{k}}=P\left(N_{-k} \mid \mu\right)-P(N \mid \mu)$ if $n_{k} \geq 1$ and $\frac{\partial P(N \mid \mu)}{\partial \mu_{k}}=-P(N \mid \mu)$ if $n_{k}=0$. For any $\left(k, k_{j}\right) \in \mathcal{K}_{C} \times \mathcal{K}_{J}$, we have

$$
\begin{aligned}
& \frac{\partial N L W\left(z_{k_{j}}^{*}, k_{j}, \mu ; \mathcal{V}^{*}\right)}{\partial \mu_{k}}=\sum_{N \in \mathbb{N}^{K}} \frac{\partial P(N \mid \mu)}{\partial \mu_{k}} \cdot\left[\int_{\bar{\Theta}} w^{*}\left(k_{j}, \theta\right) \cdot q\left(\theta \mid N, k_{j}\right) d \theta\right]-V_{k} \\
& =\sum_{N \in \mathbb{N}^{K}: n_{k} \geq 1}\left[P\left(N_{-k} \mid \mu\right)-P(N \mid \mu)\right] \cdot\left[\int_{\bar{\Theta}} w^{*}\left(k_{j}, \theta\right) \cdot q\left(\theta \mid N, k_{j}\right) d \theta\right] \\
& \quad-\sum_{N \in \mathbb{N}^{K}: n_{k}=0} P(N \mid \mu) \cdot\left[\int_{\bar{\Theta}} w^{*}\left(k_{j}, \theta\right) \cdot q\left(\theta \mid N, k_{j}\right) d \theta\right]-V_{k} \\
& =\sum_{N \in \mathbb{N}^{K}} P(N \mid \mu) \cdot\left[\int_{\bar{\Theta}} w^{*}\left(k_{j}, \theta\right) \cdot q\left(\theta \mid N_{+k}, k_{j}\right) d \theta-\int_{\bar{\Theta}} w^{*}\left(k_{j}, \theta\right) \cdot q\left(\theta \mid N, k_{j}\right) d \theta\right]-V_{k} \\
& =\sum_{N \in \mathbb{N}^{K}} P(N \mid \mu) \cdot \int_{Y} \int_{\bar{\Theta}} \int_{\Theta} w^{*}\left(k_{j}, \theta \cup \widetilde{\theta}\right) f_{k}\left(\widetilde{\theta} \mid y, k_{j}\right) d \widetilde{\theta} \prod_{k^{\prime}=1}^{K} \prod_{i_{k^{\prime}}=1}^{n_{k^{\prime}}} f_{k^{\prime}}\left(\theta_{i_{k^{\prime}}}^{\left[k^{\prime}\right]} \mid y, k_{j}\right) d \theta \cdot f_{Y}(y) d y \\
& \quad-\sum_{N \in \mathbb{N} K} P(N \mid \mu) \cdot \int_{Y} \int_{\bar{\Theta}} w^{*}\left(k_{j}, \theta\right) \prod_{k^{\prime}=1}^{K} \prod_{i_{k^{\prime}}=1}^{n_{k^{\prime}}} f_{k^{\prime}}\left(\theta_{i_{k^{\prime}}}^{\left[k^{\prime}\right]} \mid y, k_{j}\right) d \theta \cdot f_{Y}(y) d y-V_{k} . \\
& =\sum_{N \in \mathbb{N} K} P(N \mid \mu) \cdot \int_{Y} \int_{\bar{\Theta}} \int_{\Theta}\left[w^{*}\left(k_{j}, \theta \cup \widetilde{\theta}\right)-w^{*}\left(k_{j}, \theta\right)\right] \cdot f_{k}\left(\widetilde{\theta} \mid y, k_{j}\right) d \widetilde{\theta} \prod_{k^{\prime}=1}^{K} \prod_{i_{k^{\prime}}=1}^{n_{k^{\prime}}} f_{k^{\prime}}\left(\theta_{i_{k^{\prime}}}^{\left[k^{\prime}\right]} \mid y, k_{j}\right) d \theta \cdot f_{Y}(y) d y-V_{k} .
\end{aligned}
$$

From the fundamental property of the pivot mechanism, eq. (10), we have $w^{*}\left(k_{j}, \theta \cup\right.$ $\widetilde{\theta})-w^{*}\left(k_{j}, \theta\right)=\widetilde{u}\left(m_{k_{j}}^{p i v}, \theta, \widetilde{\theta}\right)$. Given (1), we obtain (12).

\footnotetext{
${ }^{44}$ We see also that the revenue of the seller is the same for any $\zeta$. If the optimum requires that $\widehat{\mu}^{\text {opt }}\left(\zeta, k_{j}\right)=$ 0 for some $\zeta$, then the revenue of type $k_{j}$ jurisdictions is thus null in equilibrium.
} 


\section{References}

[1] J. Albrecht, P. A. Gautier, and S. Vroman. Efficient Entry in Competing Auctions. American Economic Review, 104(10):3288-96, 2014.

[2] N. Allouch, J. P. Conley, and M. Wooders. Anonymous price taking equilibrium in Tiebout economies with a continuum of agents: Existence and characterization. Journal of Mathematical Economics, 45(9-10):492-510, 2009.

[3] R. J. Aumann. Subjectivity and correlation in randomized strategies. Journal of Mathematical Economics, 1(1):67-96, 1974.

[4] K. Baicker, J. Clemens, and M. Singhal. The rise of the states: U.S. fiscal decentralization in the postwar period. Journal of Public Economics, 96(11):1079-1091, 2012.

[5] H. S. Banzhaf and R. P. Walsh. Do people vote with their feet? an empirical test of tiebout. American Economic Review, 98(3):843-63, 2008.

[6] W. J. Baumol, J. C. Panzar, and R. D. Willig. Contestable Markets and the Theory of Industry Structure. Harcourt Brace Jovanovich (ed.). 1982.

[7] P. Bayer and R. McMillan. Tiebout sorting and neighborhood stratification. Journal of Public Economics, 96(11):1129-1143, 2012.

[8] R. Benabou. Workings of a City: Location, Education, and Production. The Quarterly Journal of Economics, 108(3):619-52, 1993.

[9] R. Boadway and J.-F. Tremblay. Reassessment of the Tiebout model. Journal of Public Economics, 96(11):1063-1078, 2012.

[10] D. Cass and K. Shell. Do Sunspots Matter? Journal of Political Economy, 91(2):193$227,1983$.

[11] E. Clarke. Multipart pricing of public goods. Public Choice, 11:17-33, 1971.

[12] J. Crémer and R. McLean. Full extration of the surplus in bayesian and dominant strategy auctions. Econometrica, 56(6):1247-1257, 1988.

[13] C. d'Aspremont and L.-A. Gerard-Varet. Incentives and incomplete information. Journal of Public Economics, 11(1):25-45, 1979.

[14] D. Duffie and Y. Sun. Existence of independent random matching. Annals of Applied Probability, 17(1):386-419, 2007.

[15] J. Eeckhout and P. Kircher. Sorting versus screening: Search frictions and competing mechanisms. Journal of Economic Theory, 145(4):1354-1385, 2010.

[16] B. Ellickson, B. Grodal, S. Scotchmer, and W. R. Zame. Clubs and the Market. Econometrica, 67(5):1185-1218, 1999.

[17] R. Engelbrecht-Wiggans and T. Nonnenmacher. A Theoretical Basis for 19th-Century Changes to the Port of New York Imported Goods Auction. Explorations in Economic History, 36(3):232-245, 1999.

[18] D. Epple and A. Zelenitz. The implications of competition among jurisdictions: Does tiebout need politics? Journal of Political Economy, 89(6):1197-1217, 1981.

[19] A. Gibbard. Manipulation of Voting Schemes: A General Result. Econometrica, 41(4):587-601, 1973. 
[20] T. Groves. Incentives in teams. Econometrica, 41(4):617-31, 1973.

[21] V. Guerrieri, R. Shimer, and R. Wright. Adverse selection in competitive search equilibrium. Econometrica, 78(6).

[22] J. W. Hatfield, F. Kojima, and S. D. Kominers. Strategy-proofness, investment efficiency, and marginal returns: An equivalence. Becker Friedman Institute for Research in Economics Working Paper, 2015.

[23] C. M. Hoxby. Does competition among public schools benefit students and taxpayers? American Economic Review, 90(5):1209-1238, 2000.

[24] C. M. Hoxby. Does competition among public schools benefit students and taxpayers? reply. American Economic Review, 97(5):2038-2055, 2007.

[25] P. Jehiel. Bargaining between benevolent jurisdictions or when delegation induces inefficiencies. Journal of Public Economics, 65(1):61-74, 1997.

[26] P. Jehiel. Analogy-based expectation equilibrium. Journal of Economic Theory, 123(2):81-104, 2005.

[27] P. Jehiel and L. Lamy. On discrimination in procurement auctions. CEPR Discussion Papers, 9790, 2014.

[28] P. Jehiel and L. Lamy. A mechanism design approach to the tiebout hypothesis. CEPR Discussion Papers, 10758, 2015a.

[29] P. Jehiel and L. Lamy. On discrimination in auctions with endogenous entry. American Economic Review, 105(8):2595-2643, 2015b.

[30] P. Jehiel and L. Lamy. On the use of absolute auctions and secret reserve prices. RAND Journal of Economics, 46(2):241-270, 2015c.

[31] P. Jehiel and B. Moldovanu. Efficient design with interdependent valuations. Econometrica, 69(5):1237-59, 2001.

[32] B. Julien, J. Kennes, and I. King. Bidding for Labor. Review of Economic Dynamics, $3(4): 619-649,2000$.

[33] K. Kim and P. Kircher. Efficient competition through cheap talk: the case of competing auctions. Econometrica, 83(5):1849-1875, 2015.

[34] H. Konishi. Entrepreneurial land developers: Joint production, local externalities, and mixed housing developments. Journal of Urban Economics, 75(C):68-79, 2013.

[35] L. Lamy. 'Upping the Ante': how to design efficient auctions with entry? RAND Journal of Economics, 44(2):194-214, 2013.

[36] B. Lester, L. Visschers, and R. Wolthoff. Meeting technologies and optimal trading mechanisms in competitive search markets. Journal of Economic Theory, 155:1-15, 2015.

[37] B. Lester, L. Visschers, and R. Wolthoff. Competing with asking prices. Theoretical Economics, 2016 (forthcoming).

[38] D. Levin and J. L. Smith. Equilibrium in auctions with entry. American Economic Review, 84(3):585-599, 1994.

[39] P. McAfee. Mechanism design by competing sellers. Econometrica, 61(6):1281-1312, 1993. 
[40] R. Myerson and M. Satterthwaite. Efficient mechanisms for bilateral trading. J. Econ. Theory, 29(2):265-281, 1983.

[41] R. B. Myerson. Optimal auction design. Mathematics of Operation Research, 6(1):58$73,1981$.

[42] R. B. Myerson. Population uncertainty and poisson games. International Journal of Game Theory, 27(3):375-392, 1998.

[43] M. Peters. A competitive distribution of auctions. Review of Economic Studies, 64(1):97-123, 1997.

[44] M. Peters. Noncontractible heterogeneity in directed search. Econometrica, 78(4):11731200, 2010.

[45] M. Peters and B. Szentes. Definable and Contractible Contracts. Econometrica, 80(1):363-411, 2012.

[46] J. Rochet and P. Choné. Ironing, sweeping, and multidimensional screening. Econometrica, 66(4):783-826, 1998.

[47] R. Rogerson, R. Shimer, and R. Wright. Search-theoretic models of the labor market: A survey. Journal of Economic Literature, 43(4), 2005.

[48] S. Rosen. Hedonic Prices and Implicit Markets: Product Differentiation in Pure Competition. Journal of Political Economy, 82(1):34-55, 1974.

[49] J. Rothstein. Does competition among public schools benefit students and taxpayers? comment. American Economic Review, 97(5):2026-2037, 2007.

[50] P. Samuelson. The pure theory of public expenditure. Review of Economics and Statistics, 36(4):387-389, 1954.

[51] M. A. Satterthwaite. Strategy-proofness and Arrow's conditions: Existence and correspondence theorems for voting procedures and social welfare functions. Journal of Economic Theory, 10(2):187-217, 1975.

[52] S. Scotchmer. Handbook of Public Economics, chapter Local Public Goods and Clubs, pages 1997-2042. Elsevier, 2002.

[53] R. Shimer. The assignment of workers to jobs in an economy with coordination frictions. Journal of Political Economy, 113(5):996-1025, 2005.

[54] C. Tiebout. A pure theory of local expenditures. Journal of Political Economy, 64, 1956.

[55] W. Vickrey. Counterspeculation, auctions, and competitive sealed tenders. Journal of Finance, 16(1):8-37, 1961.

[56] S. R. Williams. A characterization of efficient, bayesian incentive compatible mechanisms. Economic Theory, 14(1):155-180, 1999.

[57] R. Wilson. Game Theoretic Analysis of Trading Processes. Advances in Economic Theory : Fifth World Congress, Truman Bewley (ed.). Cambridge University Press, 1987.

[58] M. Wooders. The Theory of Clubs and Competitive Coalitions. Annual Review of Economics, 4(1):595-626, 2012. 